\title{
Electrochemical Response of Glassy Carbon Electrodes Modified using Graphene Sheets of Different Sizes
}

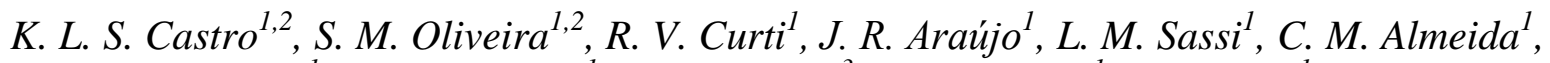 \\ E. H. M. Ferreira ${ }^{1}$, B. S. Archanjo ${ }^{1}$, M. F. Cabral ${ }^{3}$, A. Kuznetsov ${ }^{I}$, L. A. Sena ${ }^{1}$, \\ C. A. Achete ${ }^{1}$ and E. D'Elia ${ }^{2, *}$ \\ ${ }^{1}$ Instituto Nacional de Metrologia, Qualidade e Tecnologia, Avenida Nossa Senhora das Graças, 50, \\ 25250-020, Duque de Caxias, RJ, Brasil. \\ ${ }^{2}$ Instituto de Química, Universidade Federal do Rio de janeiro, Avenida Athos da Silveira Ramos, 149, \\ 21941-909, Ilha do Fundão, RJ, Brasil. \\ ${ }^{3}$ Grupo de Materiais e Superfícies Nanoestruturadas - Instituto Federal de Educação, Ciência e \\ Tecnologia do Rio de Janeiro, Rua Senador Furtado, 121, 20270-021, Rio de Janeiro, RJ, Brasil. \\ *E-mail: eliane@iq.ufrj.br
}

doi: 10.20964/2018.01.02

Received: 6 September 2017 / Accepted: 20 October 2017 / Online Published: 1 December 2017

In this study, we investigated the electrochemical behavior of reduced graphene oxide sheets (rGO) of different sizes deposited on glassy carbon electrodes. Graphene oxide sheets were produced by the exfoliation of graphite oxide in an aqueous solution by ultrasonication. Scanning electron microscopy and transmission-mode scanning electron microscopy results indicated a decrease in the size of the graphene oxide sheets with an increase in the exfoliation time or sonication power. The results of spectroscopic characterization corroborated with this behavior. X-ray diffraction analysis indicated a broadening of the peaks with crystallite size reduction while Raman spectroscopy results suggested an increase in the structural defects in the $\mathrm{sp}^{2}$ framework of graphene oxide. Complementary X-ray photoemission spectroscopy analysis indicated a decrease in the $\mathrm{sp}^{2} / \mathrm{sp}^{3}$ ratio with respect to the amount of $\mathrm{sp}^{2}$ framework in graphene oxide sheets upon decreasing the sheet size. Electrochemical analysis showed that the response of the GO-modified glassy carbon electrodes increased significantly with a decrease in the graphene oxide sheet size.

Keywords: graphene oxide; graphite oxide; Hummers' method; exfoliation time; electrochemical sensors

\section{FULL TEXT}

(C) 2018 The Authors. Published by ESG (www.electrochemsci.org). This article is an open access article distributed under the terms and conditions of the Creative Commons Attribution license (http://creativecommons.org/licenses/by/4.0/). 